\title{
Correspondence
}

\section{Psychological treatment by psychiatrists}

DeAR SIRS

The President of the College and I read Dr Richard Stern's letter (Psychiatric Bulletin, 15, 296-303) on this subject with great interest as it is a matter of much concern to the College.

We support Dr Stern's view that psychiatrists should give psychological treatments, and that by and large, they are not fully equipped to do so.

Earlier this year, the President wrote a short paper on the need for us to review the education which psychiatrists receive in both the theoretical and clinical aspects of relevant human psychology.

As Dr Stern states, in spite of the rapid development of psychotropic drugs and the more limited development of psychotherapeutic services within the National Health Service, our capacity to answer psychiatric ills remains limited. There is a public clamour for more psychological treatment and this has been endorsed by our Royal Patron (Annual Meeting, July 1991).

We have failed to ensure that a full range of psychological treatments is available in all district psychiatric services, and there is no doubt that the training issues outlined by Dr Stern must be pursued through our educational activities with trainees. The shortage of suitable trainers determines that this will be high on the list of priorities for our newly established Special Committee on Continuing Medical Education.

Undoubtedly, we will continue to produce psychiatrists with widely differing interests and commitments. The most glaring deficit in our current treatment provision as medical specialists is an ability to provide a range of psychological treatments for those patients that can be helped with them.

Both nurses and clinical psychologists are only too keen to become autonomous practitioners in fields where we are relatively inactive. While many of our colleagues in these disciplines are well trained, even expert, practitioners, there are great dangers in there not being enough psychiatrists with similar therapeutic tools. Not only do many patients dislike being passed from one professional to another, but many of our colleagues in other medical specialties prefer to make doctor to doctor referrals. There are also occasions when simultaneous psychological and pharmacological treatments are appropriate.

With regard to a Section on behavioural and cognitive psychotherapy, we are currently addressing the tension between psychotherapists of different persuasions to find a way in which all can feel valued within the Psychotherapy Section of the College. That section includes many general psychiatrists and, for the present it appears preferable to try and develop cohesion within that large group of psychiatrists where the interfaces between different kinds of psychiatric and psychological treatment can be addressed. A Working Group has been set up to address these issues, consisting of the Chairman and Secretary of the Psychotherapy Section, two cognitive/behavioural psychotherapists, a general psychiatrist and myself as Chairman.

Fiona Caldicott

Dean

\section{Royal College examination and award of qualification}

\section{DEAR SIRS}

The College's present regulations for the Membership examination require the candidate to have completed three years of training in an approved supervised training scheme. For the Part II examination candidates are allowed five attempts, and they are required to be in an approved post at the time of examination (Royal College of Psychiatrists, 1985).

With the present situation for overseas doctors, of four years limitation of stay in the UK, it may become impossible to continue in training so that one can take the benefit of five attempts, which may span over a period of a further two years and six months. (Examinations taking place in May and October/ November each year, after primary training of three years.) In a study by Bhate (1990) overseas graduates took between five and eight years to pass the Membership examination after they entered psychiatric training. This could result in unfortunate candidates being forced to leave without having any qualification to confirm the psychiatric training they received in the UK.

The Government's recent policy of creating staff psychiatrists' posts to achieve a balance (DHSS, 1988 ) is a good move. However, in the present situation there is little chance for those doctors holding staff psychiatrists' posts to appear for the Membership examination, mainly as most are not approved as training posts by the Royal College of Psychiatrists.

Doctors are also forced to opt out of psychiatry when they exhaust all their examination attempts. At present there is no alternative qualification they can 
obtain in psychiatry. To overcome this difficulty the following plan of action is suggested.

The College should consider re-introducing the DPM or equivalent qualification such as DRCPsych, to enable trainees to have more options open for them to obtain relevant qualifications. Most of the Royal Colleges in the UK conduct alternate examinations, other than Membership, and award appropriate qualifications.

\section{How to implement it}

At the present time all candidates must pass the Part I MRCPsych examination before they take Part II.

At the first attempt for Part II candidates can appear for the whole examination.

If the candidate passes some parts of the examination and fails the remaining, he should be given two options:

(a) to re-appear for the whole examination in order to obtain MRCPsych

(b) opt to hold the parts in which he/she passes and to re-appear only for the parts in which he/she failed. After passing all the parts the candidate would be awarded DPM or DRCPsych.

Once the candidate opts to take the examination in separate parts there should be no limit to the number of attempts made to complete it. After completing three years of approved training there should be no need to be in a training post to take subsequent examinations.

Those who are awarded DPM or DRCPsych should be allowed to continue as inceptors of the College.

This provision would not belittle the standard and quality of the Membership examination. In fact more doctors would continue in psychiatry and, even if they opt to become family doctors, they would be able to obtain a psychiatric qualification, which in turn would improve health care in general.

University of Leicester

V. M. MATHEW

Clinical Sciences Building

Leicester $L E 27 L X$

\section{References}

BHATE, S. (1990) Registrars and senior house officers in psychiatry. Psychiatric Bulletin 14, 342-345.

DHSS (1988) Hospital Medical Staff: Achieving a Balance. The Plan for Action. London: HMSO.

Royal College of Psychiatrists (1985) Working party for the Review of the MRCPsych: Report to the Court of Electors. London: Royal College of Psychiatrists.

\section{DeAR SiRS}

Dr Mathew makes a number of points.

With regard to overseas doctors it is true that if they are limited to four years in the United Kingdom, in line with current immigration policy, they may not be able to make the full number of attempts allowed in Part I and Part II of the MRCPsych. It should be pointed out, however, that those overseas doctors now coming to the United Kingdom are a different group to those studied by Dr Bhate, and by no means all wish to take the MRCPsych examination.

Posts approved for training are constantly monitored by the College and applications for new posts carefully considered. Changes to the Regulations have recently been published. The College accepts that there is a nzed for continuing education of all doctors: not only for the MRCPsych but also those doctors not in training grades, such as staff grade posts. A number of doctors occupying staff grade posts have been deemed eligible to sit the MRCPsych examination, but this is approved on an individual basis. To gain approval, it is necessary for these doctors to have the same range of training opportunities as those in training posts; for example, that they may obtain experience in sub-specialties of psychiatry. This clearly needs the cooperation of employing authorities.

It is also true that, in the UK at the present time, there is no alternative psychiatric qualification. The question of reintroducing the DPM (which was never administered by the College) or an examination of similar status has been considered at intervals over the years and is currently being reconsidered. Such an examination would be a major undertaking and would involve considerable expenditure of resources - both personnel and financial - and it would be important that such resources were not diverted from plans to improve the MRCPsych examination. The MRCPsych examination has been carefully designed and is constantly monitored by the elected representatives of members of the College sitting on the Court of Electors. It is felt at present that, although there is always room for refinement, the MRCPsych examination fulfils its main purposes of confirming that a doctor has reached a sufficient standard of competence to become a Member of the College, is seen by the public to have reached such a standard, and is ready to enter higher training. Any change would have to be fair to those already holding membership and not diminish the qualification.

Dr Mathew puts forward interesting ideas about offering candidates who fail two options. We believe the procedures involved would be very cumbersome, very difficult to organise, and expensive. These or similar proposals could, however, be considered.

Overall, we are not sure how helpful it is for a candidate to be encouraged to make unlimited attempts at any examination, or how fair this would be to candidates who succeed within the first few attempts, or to patients for whom the fact that the doctor treating them possesses the qualification is important. In practice, we believe it would be 